BMJ

Paediatrics Open

\title{
Antibiotic prescribing in neonatal sepsis: an Australian nationwide survey
}

\author{
Brendan McMullan (D) , ${ }^{1,2,3}$ Celia Cooper, ${ }^{4}$ Naomi Spotswood, ${ }^{5,6,7}$ Rodney James, ${ }^{8}$ \\ Cheryl Jones, ${ }^{9,10,11}$ Pamela Konecny, ${ }^{12,13}$ Christopher Blyth, ${ }^{14,15,16,17}$ \\ Thursky Karen ${ }^{2,18}$
}

To cite: McMullan B, Cooper C, Spotswood N, et al. Antibiotic prescribing in neonatal sepsis: an Australian nationwide survey. BMJ Paediatrics Open 2020;4:e000643. doi:10.1136/ bmjpo-2020-000643

- Additional material is published online only. To view please visit the journal online (http://dx.doi.org/10.1136/ bmjpo-2020-000643).

Received 15 January 2020 Revised 24 February 2020 Accepted 27 February 2020
Check for updates

\section{(C) Author(s) (or their} employer(s)) 2020. Re-use permitted under CC BY-NC. No commercial re-use. See rights and permissions. Published by BMJ.

For numbered affiliations see end of article.

Correspondence to Dr Brendan McMullan; brendanoch@yahoo.co.uk

\section{ABSTRACT}

Objective To evaluate quality and variation in antibiotic prescribing for neonatal sepsis.

Design We analysed prescribing in hospitalised neonates using the National Antimicrobial Prescribing Survey in Australian neonates from 1 January 2014 to 31 December 2018.

Setting Data from antibiotic point prevalence surveys performed in hospitals, ranging from rural hospitals to tertiary paediatric and maternity hospitals within Australia.

Patients Admitted neonates $<28$ days of age from participating hospitals.

Main outcome measures Variation and appropriateness in prescribing for neonatal sepsis and variation in dosing for gentamicin and benzylpenicillin across hospitals.

Results A total of 415 prescriptions among 214 neonates from 39 different hospitals were included. The majority of prescriptions $(342,82.4 \%)$ were for neonates $<7$ days of age. The most commonly prescribed antibiotics were gentamicin and benzylpenicillin, with 323 (77.8\%) prescriptions. Dosing variability was substantial, with doses ranging from 2 to $8 \mathrm{mg} / \mathrm{kg}$ for gentamicin (median $5 \mathrm{mg} / \mathrm{kg}$, IQR 4-5) and from 45 to $72 \mathrm{mg} /$ $\mathrm{kg}$ for benzylpenicillin (median $60 \mathrm{mg} / \mathrm{kg}$, IQR 50-60), although only $13(3.2 \%)$ and 19 (4.6\%) prescriptions were locally assessed as inappropriate or non-compliant with guidelines, respectively. At time of audit, $22 \%$ of antibiotics had been given for more than 48 hours and $9 \%$ more than 72 hours, although microbiologically confirmed infection was documented in only nine (4.2\%) neonates.

Conclusions Prescribing for neonatal sepsis was dominated by use of benzylpenicillin and gentamicin with substantial variation in dosing. A small minority had culture-confirmed infection. Efforts to standardise antibiotic dosing and duration for suspected neonatal sepsis are recommended.

\section{INTRODUCTION}

The neonatal period is the most vulnerable time of life, with neonatal mortality accounting for almost $50 \%$ of deaths in children under 5 years and approximately 2.5 million deaths globally in the first month of life in 2018. ${ }^{1}$ In Australia, despite a comparatively low neonatal mortality rate, 2 per 1000 live births compared with 18 per 1000 globally, ${ }^{1}$ perinatal infection is identified as the

\section{What is known about the subject?}

- Neonatal sepsis is an important cause of morbidity and mortality globally.

- There is considerable uncertainty about antibiotic prescribing and optimal regimens to treat neonatal sepsis.

- Current challenges include lack of epidemiological data to inform prescribing improvements.

\section{What this study adds?}

Benzylpenicillin and gentamicin accounted for more than three-quarters of antibiotics prescribed for sepsis among Australian neonates, only $4 \%$ of whom had microbiologically confirmed infection.

- There was considerable variation in dosing for both benzylpenicillin and gentamicin.

- There is an opportunity to improve prescribing and reduce unnecessary variation by targeting a smal number of drugs in the treatment of neonatal sepsis.

primary cause of neonatal death in $10.6 \%$ of Australian neonatal deaths. ${ }^{2}$ Risk factors for neonatal sepsis mortality include prematurity, lower postnatal age and immunological immaturity. ${ }^{34}$ Neonates who require hospitalisation may have additional risk factors for sepsis, including central venous catheters and mechanical ventilation. Clinical signs of neonatal sepsis are often non-specific ${ }^{5}$; thus, empiric antibiotic therapy is commonly prescribed for hospitalised neonates. ${ }^{6}$ The majority of neonates treated empirically for sepsis, however, do not have confirmed infection on final assessment. ${ }^{78}$

Unintended adverse consequences of widespread antibiotic use for neonates have been increasingly recognised, with calls for better understanding of sepsis epidemiology and efforts to promote judicious prescribing. ${ }^{9}$ The Kaiser Permanente Early Onset Sepsis Calculator is one tool used to predict risk of microbiologically confirmed infection and reduce unnecessary investigations and 
antibiotic therapy with some success. ${ }^{10}$ This only applies to neonates with early-onset sepsis (EOS), however, and similar tools for late-onset sepsis (LOS) are lacking.

In recognition that the epidemiology of sepsis in neonates varies with age, it is commonly divided into EOS and LOS. While the risk and microbiology of sepsis in the first few days of life are reported to be substantially influenced by antenatal and intrapartum factors, sepsis beyond the first few days is likely influenced to a greater extent by the postnatal environment, although the utility of this division across global settings has been challenged. ${ }^{11}$ The definition of EOS versus LOS also varies between studies. The Australian and New Zealand Neonatal Network defines EOS as neonatal sepsis with initial symptoms beginning <48 hours of life (2 days). ${ }^{12}$ Common pathogens identified in EOS have been better characterised than those causing LOS in Australia, although both have been described in the UK. ${ }^{613}$

In this study we aimed to report on antimicrobial prescribing for neonatal sepsis of all types, using a national data set from Australia. Antibiotic use and appropriateness for indications other than sepsis, such as prophylaxis, are not included in this analysis.

\section{METHODS}

We obtained de-identified data from the National Antimicrobial Prescribing Survey (NAPS) database of point prevalence prescribing surveys for Australian hospitals from all six Australian states and two territories (from 1 January 2014 to 31 December 2018). ${ }^{14}$ Participation in these surveys is voluntary and data are submitted through a web-based interface to a central database. ${ }^{14}$ Hospitals can participate in these surveys whenever they choose, although most participate annually. Survey methodology has been described previously ${ }^{15} 16$; in brief, the data set includes antimicrobial usage (agent, dose, frequency, route); baseline demographics (age, gender, hospital location, funding type (public/private), hospital size); infection site and type; adherence with local or national Australian antibiotic guidelines; and antimicrobial appropriateness. Local guidelines include any locally endorsed hospital, network or regional guidelines, other than the nationally used Therapeutic Guidelines. ${ }^{17}$ Assessors can choose to select from various potential reasons for inappropriate prescribing, including 'spectrum too broad', 'spectrum too narrow', 'incorrect route', 'incorrect dose or frequency', 'incorrect duration', 'allergy mismatch' or 'microbiology mismatch'; these are not mutually exclusive. Appropriateness assessments were conducted by trained local surveyors as described previously. ${ }^{18}{ }^{19} \mathrm{~A}$ score of 1 or 2 is considered to be 'appropriate' and 3 or 4 as 'inappropriate' (online supplementary appendix figure 1). For this study, individual prescription data were extracted for patients surveyed aged 0 days to less than 28 days of age, where the indication group for antibiotic was recorded as 'sepsis' and weight was recorded (to enable dose calculation). The principal unit of analysis was individual prescription. Dosing of gentamicin and benzylpenicillin was rounded to whole $\mathrm{mg} / \mathrm{kg}$. Year of survey was analysed by calendar year. We designated EOS by age criteria as sepsis indication for antibiotics with age $<2$ completed days. LOS was defined by age $\geq 2$ days at antibiotic commencement or if age $>7$ days at audit date if antibiotic start date was missing. Prematurity was defined as gestational age $<37$ weeks. Dedicated children's hospitals, maternity hospitals or combined maternity/children's hospitals were classed as specialist hospitals.

\section{Patient involvement}

Patients were not involved in the design or analysis of this study.

\section{Statistical analysis}

Categorical variables and proportions were summarised and compared between groups using $\chi^{2}$ test. A $p$ value of 0.05 (two-tailed) was deemed statistically significant. Dosing variability in $\mathrm{mg} / \mathrm{kg}$ and antibiotic duration by groups were compared using Wilcoxon rank-sum tests. Statistical analyses and graphs were done using Stata V.16.0.

\section{RESULTS}

\section{Demographics}

Among 884 neonatal prescriptions between 1 January 2014 and 31 December 2018, 415 (46.9\%) prescriptions were recorded as given for sepsis. These prescriptions were for 214 neonates from 39 hospitals. All Australian states and territories were represented apart from the Northern Territory. Hospitals included specialist women's hospitals or paediatric hospitals with tertiary neonatal intensive care units, as well as general public and private hospitals. A large majority of included hospitals (88.7\%) were in metropolitan areas. Female neonates accounted for $184(44.3 \%)$ prescriptions and the rest were for male neonates. The number of prescriptions varied by year (table 1). The majority of prescriptions were for neonates $<7$ days of age $(342,82.4 \%)$. Where this could be assessed, $71 \%$ (245 of 345) of prescriptions were for EOS and 29\% (100 of 345) for LOS. Premature neonates accounted for 123 prescriptions (54.4\% of prescriptions for which gestational age was available). The median weight was $2.9 \mathrm{~kg}$ (IQR 1.9-3.4). Demographic details are shown in full in table 1 .

\section{Antibiotic type and duration}

The Drug Utilization $90 \%$, which refers to the number of antibiotics accounting for $90 \%$ of usage when ranked by frequency, included a total of five antibiotics. In descending order these were gentamicin, benzylpenicillin, cefotaxime, ampicillin and flucloxacillin. Twenty $(9.3 \%)$ neonates were prescribed one antimicrobial for sepsis, $187(87.4 \%)$ neonates two antimicrobials and $7(3.3 \%)$ neonates three antimicrobials. There were $323(77.8 \%)$ prescriptions of either gentamicin 


\begin{tabular}{|c|c|c|}
\hline Demographics & $\begin{array}{l}\text { Total } \\
\text { prescriptions } \\
\text { (415) }\end{array}$ & $\%$ \\
\hline \multicolumn{3}{|l|}{ Gestational age (weeks) } \\
\hline$<25$ & 20 & 4.8 \\
\hline 25 to $<30$ & 32 & 7.7 \\
\hline 30 to $<35$ & 52 & 12.5 \\
\hline 35 to $<37$ & 21 & 5.1 \\
\hline$\geq 37$ & 101 & 24.3 \\
\hline Not stated & 189 & 45.5 \\
\hline \multicolumn{3}{|l|}{ Postnatal age (days) } \\
\hline$<7$ & 342 & 82.4 \\
\hline 7 to $<15$ & 38 & 9.2 \\
\hline 15 to $<28$ & 35 & 8.4 \\
\hline Sex: female & 184 & 44.3 \\
\hline Median (IQR) weight (kg) & $2.9(1.9-3.4)$ & NA \\
\hline \multicolumn{3}{|l|}{ Records by year of survey } \\
\hline 2014 & 56 & 13.5 \\
\hline 2015 & 118 & 28.4 \\
\hline 2016 & 63 & 15.2 \\
\hline 2017 & 87 & 21.0 \\
\hline 2018 & 91 & 21.9 \\
\hline In NICU/ICU* & 174 & 41.8 \\
\hline \multicolumn{3}{|l|}{ Hospital type } \\
\hline Specialist women's & 161 & 38.8 \\
\hline Specialist children's & 76 & 18.3 \\
\hline $\begin{array}{l}\text { Specialist women's and } \\
\text { children's }\end{array}$ & 31 & 7.5 \\
\hline Other public hospitals & 134 & 32.2 \\
\hline Private hospitals & 6 & 1.5 \\
\hline Unpeered/unknown & 7 & 1.7 \\
\hline \multicolumn{3}{|l|}{ Hospital location } \\
\hline Major city & 368 & 88.7 \\
\hline Inner regional & 28 & 6.7 \\
\hline Outer regional & 19 & 4.6 \\
\hline
\end{tabular}

${ }^{*} \mathrm{NICU} / \mathrm{ICU}$ status not stated for 77 prescriptions.

ICU, intensive care unit; NA, not applicable; NICU, neonatal intensive care units.

or benzylpenicillin, and 133 of $214(62.1 \%)$ neonates were prescribed both benzylpenicillin and gentamicin. Antibiotics most frequently prescribed in total and for EOS/LOS are shown in tables 2 and 3. At audit, $48 \%$ of antibiotics had been given for $>24$ hours, $22 \%$ for $>48$ hours and $9 \%$ for $>72$ hours (figure 1 ). Microbiologically confirmed infection was documented in only 15 $(3.6 \%)$ prescriptions among $9(4.2 \%)$ neonates (table 4$)$. Antibiotic duration was significantly longer in specialist hospitals (median 2 days, IQR 1-3 days) compared with non-specialist hospitals (median 1 day, IQR 1-1.5 days; $\mathrm{p}<0.0001) \quad$ (online supplementary appendix figure 2) but did not differ by metropolitan versus rural hospital prescriptions.

\section{Appropriateness and guideline compliance}

Overall 400 of 415 (96.4\%) prescriptions were assessed by local hospital auditors as appropriate and $13(3.1 \%)$ inappropriate, with $330(79.5 \%)$ prescriptions assessed as compliant with local guidelines and 53 (12.8\%) prescriptions as compliant with the national Therapeutic Guidelines. ${ }^{20}$ Nineteen $(4.6 \%)$ prescriptions were assessed as non-compliant with guidelines. Detailed appropriateness and compliance assessment is displayed in online supplementary appendix table 1. Appropriateness was reported as similar for specialist and non-specialist hospitals $(98 \%$ vs $95 \%$ appropriate), but reported guideline compliance was significantly higher in specialist hospitals (97.3\% compared with $91.8 \%$, respectively; $\mathrm{p}=0.013$ ). Metropolitan hospitals had higher reported appropriateness compared with rural hospitals $(98.1 \%$ vs $87.2 \%$; $\mathrm{p}=0.0001)$ and guideline compliance $(96.9 \%$ vs $83 \%$; $\mathrm{p}<0.0001)$.

\section{Dosing variability: gentamicin and benzylpenicillin}

Gentamicin dosing and frequency information was available for 178 prescriptions. The dose varied from 2 to $8 \mathrm{mg} / \mathrm{kg}$ (median $5 \mathrm{mg} / \mathrm{kg}$, IQR 4-5). Gentamicin dose variability is shown in figure 2A. Benzylpenicillin dosing and frequency information was available for 143 prescriptions. The dose varied from 45 to $72 \mathrm{mg} / \mathrm{kg}$ (median $60 \mathrm{mg} / \mathrm{kg}$, IQR 50-60). Benzylpenicillin dose variability is shown in figure 2B. Dosing frequency also varied, although the majority of neonates received 24-hourly gentamicin and 12-hourly benzylpenicillin (online supplementary appendix table 2). Dosing for benzylpenicillin did not differ by hospital location (metropolitan vs rural) or by specialist/non-specialist hospital. Gentamicin dosing was significantly lower $(p<0.0001)$ in non-specialist hospitals (median $4.4 \mathrm{mg} / \mathrm{kg} /$ dose, IQR $3.9-5 \mathrm{mg} / \mathrm{kg}$ / dose) compared with specialist hospitals (median $5 \mathrm{mg}$ / $\mathrm{kg} /$ dose, IQR $4.6-5.1 \mathrm{mg} / \mathrm{kg} /$ dose). Gentamicin dosing was also significantly lower $(\mathrm{p}<0.0001)$ in rural hospitals (median $3.9 \mathrm{mg} / \mathrm{kg} /$ dose, IQR $2.5-4.5 \mathrm{mg} / \mathrm{kg} / \mathrm{dose}$ ) compared with metropolitan hospitals (median $5 \mathrm{mg}$ / $\mathrm{kg} /$ dose, IQR $4.5-5 \mathrm{mg} / \mathrm{kg} /$ dose).

\section{DISCUSSION}

In this study, the largest nationwide analysis of prescribing for neonatal sepsis in Australia, we found a strong preference for use of gentamicin and benzylpenicillin for treatment of neonatal sepsis/risk of sepsis but substantial variation in dosing of these agents. The study included a broad range of gestational ages and a variety of hospital types across Australia, but most neonates treated for sepsis were $<7$ days of age. Only $4 \%$ of neonates had microbiologically confirmed infection. Locally assessed 
Table 2 Antibiotics by frequency prescribed

\begin{tabular}{|c|c|c|c|}
\hline Antibiotics & Prescriptions* & Percentage & Cumulative percentage \\
\hline Gentamicin & 179 & 43.1 & 43.1 \\
\hline Benzylpenicillin (penicillin G) & 144 & 34.7 & 77.8 \\
\hline Cefotaxime & 26 & 6.3 & 84.1 \\
\hline Ampicillin & 18 & 4.3 & 88.4 \\
\hline Flucloxacillin & 13 & 3.1 & 91.6 \\
\hline Vancomycin & 13 & 3.1 & 94.7 \\
\hline Amoxicillin (amoxycillin) & 9 & 2.2 & 96.9 \\
\hline Meropenem & 6 & 1.45 & 98.3 \\
\hline Benzathine penicillin & 4 & 0.96 & 99.3 \\
\hline Amphotericin B liposomal & 1 & 0.24 & 99.5 \\
\hline Azithromycin & 1 & 0.24 & 99.8 \\
\hline Ceftriaxone & 1 & 0.24 & 100 \\
\hline
\end{tabular}

${ }^{*}$ Total $=415$ prescriptions in 214 neonates.

appropriateness and guideline compliance were high but varied by hospital type and location.

Large-scale analysis of antibiotic prescribing and appropriateness for neonatal sepsis has not been reported in Australia. Information on neonatal empiric guideline use $^{21}$ and prescribing ${ }^{22}$ has been reported from selected

Table 3 Top 5 antibiotics by frequency prescribed and sepsis type

\begin{tabular}{|c|c|c|}
\hline Antibiotic: all & $\begin{array}{l}\text { Prescriptions } \\
\text { Total=415, n (\%) }\end{array}$ & $\begin{array}{l}\text { Cumulative } \\
\text { percentage }\end{array}$ \\
\hline Gentamicin & $179(43.1)$ & 43.1 \\
\hline $\begin{array}{l}\text { Benzylpenicillin } \\
\text { (penicillin G) }\end{array}$ & $144(34.7)$ & 77.8 \\
\hline Cefotaxime & $26(6.3)$ & 84.1 \\
\hline Ampicillin & $18(4.3)$ & 88.4 \\
\hline Flucloxacillin & $13(3.1)$ & 91.6 \\
\hline Antibiotic: EOS & $\begin{array}{l}\text { Prescriptions } \\
\text { Total=245, n (\%) }\end{array}$ & $\begin{array}{l}\text { Cumulative } \\
\text { percentage }\end{array}$ \\
\hline Gentamicin & $119(48.6)$ & 48.6 \\
\hline $\begin{array}{l}\text { Benzylpenicillin } \\
\text { (penicillin G) }\end{array}$ & $100(40.8)$ & 89.4 \\
\hline Ampicillin & $12(4.9)$ & 94.3 \\
\hline Amoxicillin & $5(2)$ & 96.3 \\
\hline Benzathine penicillin & $3(1.2)$ & 97.6 \\
\hline Antibiotic: LOS & $\begin{array}{l}\text { Prescriptions } \\
\text { Total=100,n (\%) }\end{array}$ & $\begin{array}{l}\text { Cumulative } \\
\text { percentage }\end{array}$ \\
\hline Gentamicin & $31(31)$ & 31 \\
\hline Cefotaxime & $18(18)$ & 49 \\
\hline $\begin{array}{l}\text { Benzylpenicillin } \\
\text { (penicillin G) }\end{array}$ & $16(16)$ & 65 \\
\hline Vancomycin & $11(11)$ & 76 \\
\hline Flucloxacillin & $10(10)$ & 86 \\
\hline
\end{tabular}

EOS, early-onset sepsis; LOS, late-onset sepsis. large neonatal intensive care units, but this excludes many health services providing neonatal care. Hospitals use a variety of different guidelines for selection and dosing of empiric antibiotic therapy in neonates..$^{21-24}$ Benzylpenicillin and gentamicin are recommended for empiric treatment of neonatal sepsis in current national guidelines ${ }^{20}$ and are appropriate empiric therapy for the majority of organisms responsible for EOS in Australia. ${ }^{6}$ This study confirms these are frequently used currently, although with considerable variation in administration.

In our study, only a small number of sepsis prescriptions (4\%) were for microbiologically confirmed infections. While antibiotics may be life-saving, they are also associated with adverse effects, including impact on the neonate microbiome, ${ }^{25}$ with potential long-term atopic and metabolic consequences of antibiotics in early life including asthma ${ }^{26}$ and obesity. ${ }^{27} \mathrm{~A}$ rational prescribing approach includes 'making a (differential) diagnosis, estimating prognosis, establishing the goals of therapy, selecting the most appropriate treatment and monitoring the effects

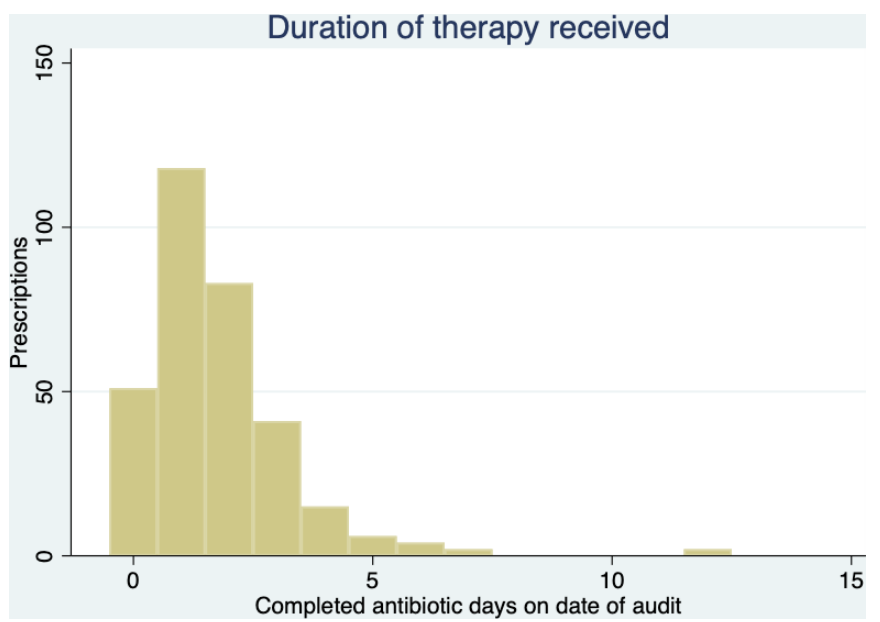

Figure 1 Duration of therapy (completed antibiotic days at audit date). 


\begin{tabular}{lcc}
$\begin{array}{l}\text { Table } 4 \\
\text { infection }\end{array}$ & Neonates with microbiologically confirmed \\
\hline $\begin{array}{l}\text { Microbiologically } \\
\text { confirmed infection } \\
\text { type }\end{array}$ & Prescriptions (\%) & Neonates (\%) \\
\hline $\begin{array}{l}\text { Coagulase-negative } \\
\text { staphylococcal } \\
\text { bacteraemia }\end{array}$ & $7(1.7)$ & $5(2.3)$ \\
$\begin{array}{l}\text { Candidaemia* } \\
\text { Other† }\end{array}$ & $4(1.0)$ & $2(0.9)$ \\
\hline Total $\ddagger$ & $4(1.0)$ & $2(0.9)$ \\
\hline
\end{tabular}

*One infant had Candida glabrata and coagulase-negative Staphylococcus in blood cultures and was treated with liposomal amphotericin B. The other had C. albicans in blood culture. This infant was treated with fluconazole for indication 'candidaemia' and benzylpenicillin and cefotaxime for indication 'sepsis'. †One infant had Gram-positive cocci detected in blood culture, awaiting species confirmation at time of audit. The other had pneumonia with Klebsiella oxytoca isolated from endotracheal tube aspirate culture.

‡Only one infant with microbiologically confirmed infection met the criteria for early-onset sepsis, with as yet unidentified Grampositive cocci in blood culture.

of that treatment'. ${ }^{28}$ In contrast, prescribing for risk of sepsis in neonates generally requires commencement of antibiotic therapy, despite the fact that most will not have culture-confirmed infection. Current challenges in refining and standardising therapy include a lack of datadriven consensus definition for neonatal sepsis and lack of sufficiently rapid, sensitive and specific diagnostic tests during the early phase of illness to rule in/out serious infection. ${ }^{29}$ More sensitive and specific rapid diagnostic tools requiring minimal sample volumes are required to further improve care and outcomes for suspected neonatal sepsis.

Dosing variation in the small number of drugs commonly used to treat neonatal sepsis represents an opportunity to standardise and potentially improve care. A survey of six Australian tertiary neonatal units conducted in 2012 demonstrated substantial variation in dosing for vancomycin and gentamicin in neonates, with gentamicin, benzylpenicillin and vancomycin the most commonly prescribed drugs for systemic therapy. ${ }^{22}$ A survey of neonatal intensive care units from 21 European countries, with 586 systemic antibiotic prescriptions for infants up to 90 days of age, reported a tendency of overdosing penicillins and underdosing vancomycin and gentamicin, relative to guidelines. ${ }^{30}$ Although we found variation both above and below recommended doses for benzylpenicillin and gentamicin in neonates treated for sepsis, we also found a tendency of underdosing gentamicin in non-specialist and non-metropolitan hospitals, a cause for concern. One potential source of dosing variation is use of birth weight rather than measured weight in neonates and rounding of doses for drug dose calculations. In one study of more than 9000 neonates over a 20-year period, weight error due to digit bias (whereby
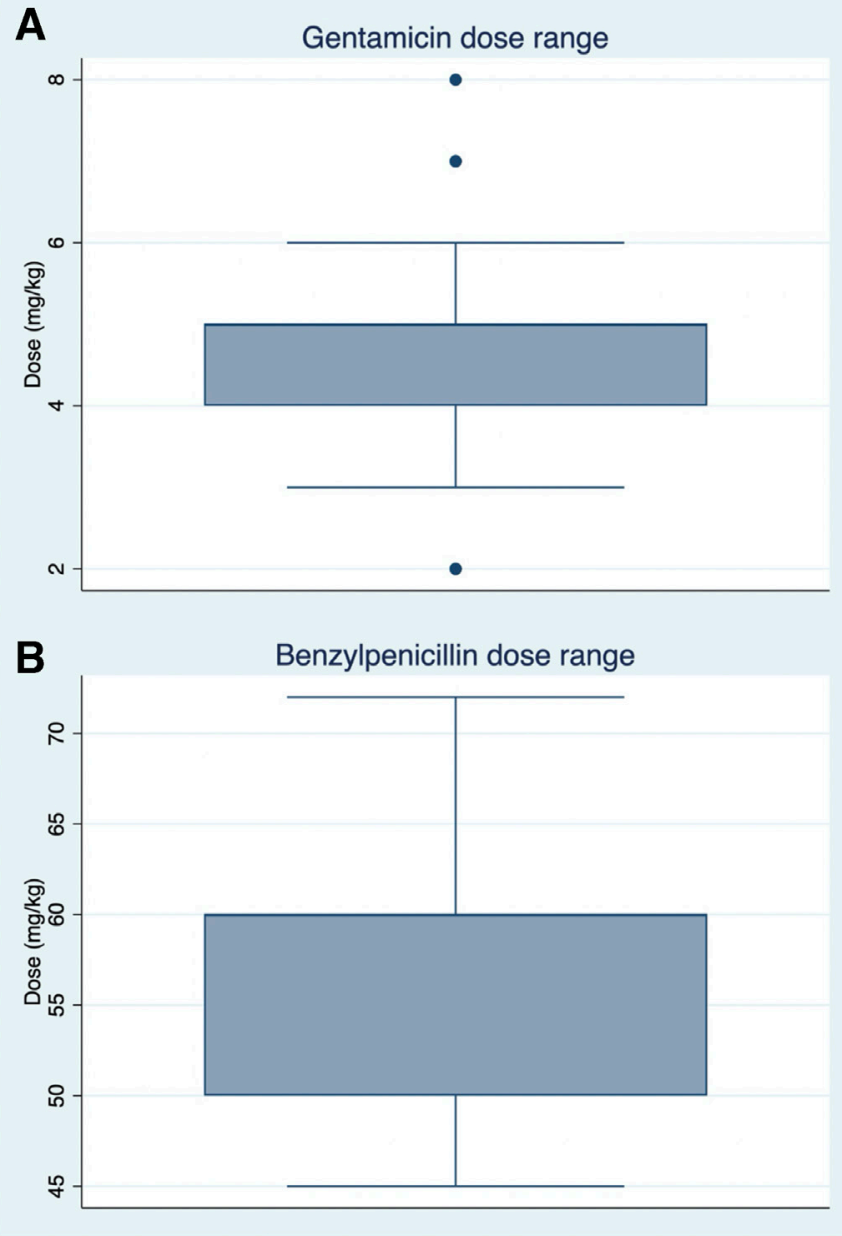

Figure 2 Individual dose ranges for gentamicin and benzylpenicillin (whole $\mathrm{mg} / \mathrm{kg}$ ). (A) Gentamicin ( $\mathrm{n}=178$ ): median dose $5 \mathrm{mg} / \mathrm{kg}$ (IQR $4-5 \mathrm{mg} / \mathrm{kg}$ ). Dots represent outliers; one $52 \mathrm{mg} / \mathrm{kg}$ dose omitted from the figure, as apparent 10-fold error. (B) Benzylpenicillin ( $n=143)$ : median dose $60 \mathrm{mg} / \mathrm{kg}$ (IQR 50-60); one $6 \mathrm{mg} / \mathrm{kg}$ dose omitted from the figure, as apparent 10 -fold error.

round numbers are favoured) improved over 20 years but was still evident in neonates between 1000 and $4500 \mathrm{~g}$ at $\leq 5 \% .{ }^{31}$ Relative to body size, this phenomenon accounts for additional variation not seen in the adult population, where standardised doses are used, and the implications of this variation for research and practice improvement remain insufficiently understood.

Although local and international guidelines available for management of neonatal sepsis are available, ${ }^{32}$ national guidelines for neonatal sepsis prescribing did not exist during the period of this study. These are now available, however, with national Therapeutic Guidelines ${ }^{20}$ updated in mid-2019 to include recommendations for treatment of neonatal sepsis and selected other neonatal infections. These subscription guidelines are widely available in Australian hospitals and contain evidence-based dosing recommendations, selected by expert consensus group review and dosing aligned with recommendations from the Australasian Neonatal Medicines Formulary (ANMF) group. The ANMF group provides freely 
available, evidence-based and regularly updated medicine guidelines for neonates. ${ }^{33}$ Both the ANMF $^{33}$ and Therapeutic Guidelines ${ }^{20}$ recommend dosing of $5 \mathrm{mg}$ / $\mathrm{kg}$ for gentamicin and $60 \mathrm{mg} / \mathrm{kg}$ for benzylpenicillin (90 $\mathrm{mg} / \mathrm{kg}$ for meningitis), with frequency dependent on gestational and postnatal age. These may serve as references for future assessment of neonatal sepsis prescribing as national standard recommendations.

Over $20 \%$ of antibiotics had been prescribed for $>48$ hours at time of audit, although only $4 \%$ of neonates had microbiologically confirmed infection documented. Given that the majority of potential pathogens in neonatal sepsis are identified within $36-48$ hours, ${ }^{34}$ this may represent excessive antibiotic therapy and provides an opportunity for quality improvement. Hospital antimicrobial stewardship teams may not include neonatal pharmacologists or neonatal infection specialists, and thus the recently nationally available guidelines for sepsis and antimicrobial use in neonates, listed above, may provide a more robust framework for assessment and promotion of the most appropriate therapy. Since most prescribing for neonatal sepsis in Australia includes only a small number of drugs, as we have shown, efforts to improve consistency of prescribing, particularly with regard to dosing in sepsis therapy, should be possible.

Over $95 \%$ of therapy for neonatal sepsis was deemed appropriate by local assessors and over 90\% deemed compliant with guidelines in this study. This is similar to a previous Australian study in which only $4 \%$ of prescriptions were considered inappropriate. ${ }^{22}$ Compliance was also deemed high in this study, largely based on compliance with local guidelines. Although $12.8 \%$ of prescriptions were reported as compliant with Therapeutic Guidelines, these specifically excluded recommendations for neonates at the time of this study. Given the substantial dosing variation and potentially excessive durations described above, these findings suggest challenges with local assessment of appropriateness and guideline compliance of therapy for sepsis in neonates. It is difficult to say whether the degree of variation in prescribing demonstrated here led to suboptimal outcomes. Nonetheless, we question whether such diversity in dosing for a handful of well-known drugs can be said to be optimal therapy.

In this study we were unable to compare prescribing with local guidelines used within each hospital, and this is a substantial limitation, although it reinforces our point that diversity of guidelines is a major challenge to achieving standardised prescribing. In addition to this, as we have described above, it is possible that compliance and appropriateness have been overattributed by local assessors, although these may in future be ameliorated by new national guidelines and further assessor training. We also do not currently have information on the proportion of neonates in each hospital who were not prescribed antibiotics. Weight was not a mandatory field in the NAPS tool at the time of survey and we did not include neonates who did not have a weight recorded, as we required this to calculate doses by weight for this study. For future surveys, mandatory inclusion of weight could improve the tool's utility for antimicrobial prescribing to neonates and children. Gestational age was not stated in $45.5 \%$ of cases, and this also limits our ability to interpret prescribing patterns and appropriateness with reference to this. We also made assumptions based on age to calculate EOS and LOS as this was not directly entered by local assessors, and these results must be interpreted with caution. The data here may not be applicable to countries with high rates of drugresistant organisms causing neonatal sepsis ${ }^{11}{ }^{35}$ as these are likely to have different prescribing choices. In this study, we did not have access to local antibiograms, but the proportions of gentamicin and penicillin used here are in keeping with available national data showing relatively low rates of drug-resistant pathogens in neonatal sepsis. ${ }^{36}$

\section{CONCLUSIONS}

In this nationwide survey we have identified substantial variability in dosing of benzylpenicillin and gentamicin, the two most commonly prescribed antibiotics for neonatal sepsis in this study. Only a small minority of neonates treated for sepsis have culture-confirmed infection. Efforts to optimise therapy for treatment of neonatal sepsis and reach consensus for therapy, including understanding prescribing practices and implementing national guidelines, are recommended.

\section{Author affiliations}

${ }^{1}$ Immunology and Infectious Diseases, Sydney Children's Hospital Randwick, Sydney, New South Wales, Australia

${ }^{2}$ National Centre for Infections in Cancer, University of Melbourne, Melbourne, Victoria, Australia

${ }^{3}$ School of Women's and Children's Health, University of New South Wales, Sydney, New South Wales, Australia

${ }^{4}$ Department of Infectious Diseases, Women's and Children's Hospital, North Adelaide, South Australia, Australia

${ }^{5}$ Burnet Institute, Melbourne, Victoria, Australia

${ }^{6}$ Department of Medicine, University of Melbourne, Melbourne, Victoria, Australia ${ }^{7}$ Department of Paediatrics, Royal Hobart Hospital, Hobart, Tasmania, Australia

${ }^{8}$ National Centre for Antimicrobial Stewardship, Melbourne, Victoria, Australia

${ }^{9}$ Faculty of Medicine and Health, The University of Sydney, Sydney, New South Wales, Australia

${ }^{10}$ Murdoch Children's Research Institute, Melbourne, Victoria, Australia

${ }^{11}$ Department of Paediatrics, University of Melbourne, Melbourne, Victoria, Australia

${ }^{12}$ Infectious Diseases, Immunology and Sexual Health, St George Hospital, Kogarah, Sydney, New South Wales, Australia

${ }^{13}$ St George and Sutherland Clinical School, University of New South Wales, Sydney, New South Wales, Australia

${ }^{14}$ School of Paediatrics and Child Health, University of Western Australia, Subiaco, Western Australia, Australia

${ }^{15}$ Wesfarmers Centre of Vaccines and Infectious Diseases, Telethon Kids Institute, Perth, Western Australia, Australia

${ }^{16}$ Department of Paediatric Infectious Diseases, Perth Children's Hospital, Perth, Western Australia, Australia

${ }^{17}$ Department of Microbiology, PathWest Laboratory Medicine, Perth, Western Australia, Australia

${ }^{18}$ Infectious Diseases Service and Peter MacCallum Cancer Centre, Melbourne, Victoria, Australia

Acknowledgements We acknowledge the support of the Australian Commission on Safety and Quality in Health Care, the NAPS staff and programme, and NAPS assessors and participating hospitals. 
Contributors BM planned, conducted, analysed, wrote, revised and submitted the study. CC, NS, RJ, CJ, PK and CB analysed, cowrote and revised the study. TK planned, analysed, cowrote and revised the study.

Funding This work was supported by a PhD scholarship from the University of Melbourne for BM. Since 2013 the Australian Commission on Safety and Quality in Health Care has supported the NAPS programme for the AURA Surveillance System. CB is supported by an NHMRC Career Development Fellowship (APP1111596). There was no direct funding for the preparation or revision of this manuscript. NS is supported by a PhD scholarship from the Australian Commonwealth Government.

Competing interests None declared.

Patient consent for publication Not required.

Ethics approval Ethics approval as a quality assurance project was obtained from the Melbourne Health Human Research Ethics Committee to coordinate the NAPS (no QA2013066).

Provenance and peer review Not commissioned; externally peer reviewed.

Data availability statement All data relevant to the study are included in the article or uploaded as supplementary information.

Open access This is an open access article distributed in accordance with the Creative Commons Attribution Non Commercial (CC BY-NC 4.0) license, which permits others to distribute, remix, adapt, build upon this work non-commercially, and license their derivative works on different terms, provided the original work is properly cited, appropriate credit is given, any changes made indicated, and the use is non-commercial. See: http://creativecommons.org/licenses/by-nc/4.0/.

ORCID iD

Brendan McMullan http://orcid.org/0000-0001-5144-3416

\section{REFERENCES}

1 UNIGME. Levels \& Trends in Child Mortality: Report 2019, 2019. Available: https://childmortality.org/reports [Accessed 13 Nov 2019].

2 AlHW. Australian Institute of health and welfare 2019. stillbirths and neonatal deaths in Australia 2015 and 2016: in brief. perinatal statistics series No. 36. cat. No. per 102. Canberra: AlHW, 2019.

3 Raymond SL, Stortz JA, Mira JC, et al. Immunological defects in neonatal sepsis and potential therapeutic approaches. Front Pediatr 2017;5:14.

4 Ghazal P, Dickinson P, Smith CL. Early life response to infection. Curr Opin Infect Dis 2013;26:213-8.

5 Gerdes JS. Diagnosis and management of bacterial infections in the neonate. Pediatr Clin North Am 2004;51:939-59.

6 Singh T, Barnes EH, Isaacs D, et al. Early-Onset neonatal infections in Australia and New Zealand, 2002-2012. Arch Dis Child Fetal Neonatal Ed 2019;104:F248-52.

7 Fjalstad JW, Stensvold HJ, Bergseng H, et al. Early-Onset sepsis and antibiotic exposure in term infants: a nationwide populationbased study in Norway. Pediatr Infect Dis J 2016;35:1-6.

8 Schulman J, Profit J, Lee HC, et al. Variations in neonatal antibiotic use. Pediatrics 2018;142:e20180115.

9 Lavoie PM, Popescu CR, Molyneux EM, et al. Rethinking management of neonates at risk of sepsis. The Lancet 2019;394:279-81.

10 Strunk T, Buchiboyina A, Sharp M, et al. Implementation of the neonatal sepsis calculator in an Australian tertiary perinatal centre. Neonatology 2018;113:379-82.

11 Chaurasia S, Sivanandan S, Agarwal R, et al. Neonatal sepsis in South Asia: huge burden and spiralling antimicrobial resistance. BMJ 2019;364:k5314.

12 Chow SSW, Creighton P, Chambers GM, et al. Report of the Australian and New Zealand neonatal network 2017. Sydney, 2019.

13 Cailes B, Kortsalioudaki C, Buttery J, et al. Epidemiology of UK neonatal infections: the neonIN infection surveillance network. Arch Dis Child Fetal Neonatal Ed 2018;103:F547-53.

14 National Centre for Antimicrobial Stewardship and Australian Commission on Safety and Quality in Health Care. Antimicrobial prescribing practice in Australian hospitals: results of the 2016 Hospital national antimicrobial prescribing survey. Sydney: ACSQHC, 2018.

15 National Centre for Antimicrobial Stewardship and Australian Commission on Safety and Quality in Health Care. Antimicrobial prescribing practice in Australian hospitals: results of the 2017 Hospital national antimicrobial prescribing survey. Sydney: ACSQHC, 2018.

16 McMullan BJ, Hall L, James R, et al. Antibiotic appropriateness and guideline adherence in hospitalized children: results of a nationwide study. J Antimicrob Chemother 2019;2.

17 Therapeutic Guidelines. Therapeutic guidelines: antibiotic, version 15. Melbourne, 2015. https://www.tg.org.au/

18 Spiotta AM, James RF, Lowe SR, et al. Balloon-augmented Onyx embolization of cerebral arteriovenous malformations using a dual-lumen balloon: a multicenter experience. J Neurointerv Surg 2015;7:721-7.

19 Constantinescu IC, Popa OP, Popa LO, et al. A new feather mite species of the genus Trouessartia Canestrini, 1899 (Acarina, Trouessartiidae) - an integrative description (morphology and DNA barcoding data). Zookeys 2018;789:19-35.

20 Therapeutic Guidelines. Therapeutic guidelines: antibiotic, version 16. Melbourne, 2019. https://www.tg.org.au/

21 Carr JP, Burgner DP, Hardikar RS, et al. Empiric antibiotic regimens for neonatal sepsis in Australian and New Zealand neonatal intensive care units. J Paediatr Child Health 2017;53:680-4.

22 Osowicki J, Gwee A, Noronha J, et al. Australia-Wide point prevalence survey of antimicrobial prescribing in neonatal units. Pediatr Infect Dis J 2015;34:e185-90.

23 Leroux S, Zhao W, Bétrémieux P, et al. Therapeutic guidelines for prescribing antibiotics in neonates should be evidence-based: a French national survey. Arch Dis Child 2015;100:394-8.

24 Liem TBY, Krediet TG, Fleer A, et al. Variation in antibiotic use in neonatal intensive care units in the Netherlands. J Antimicrob Chemother 2010;65:1270-5.

25 Cotten CM. Adverse consequences of neonatal antibiotic exposure. Curr Opin Pediatr 2016;28:141-9.

26 Droste JHJ, Wieringa MH, Weyler JJ, et al. Does the use of antibiotics in early childhood increase the risk of asthma and allergic disease? Clin Exp Allergy 2000;30:1548-53.

27 Cox LM, Blaser MJ. Antibiotics in early life and obesity. Nat Rev Endocrinol 2015;11:182-90.

28 Maxwell SRJ. Rational prescribing: the principles of drug selection. Clin Med 2016;16:459-64.

29 Vergnano S, Seale AC, Fitchett EJA, et al. Serious bacterial infections in neonates: improving reporting and case definitions. Int Health 2017;9:148-55.

30 Metsvaht $\mathrm{T}$, Nellis $\mathrm{G}$, Varendi $\mathrm{H}$, et al. High variability in the dosing of commonly used antibiotics revealed by a Europe-wide point prevalence study: implications for research and dissemination. BMC Pediatr 2015;15:41.

31 Emmerson AJ, Roberts SA. Rounding of birth weights in a neonatal intensive care unit over 20 years: an analysis of a large cohort study. BMJ Open 2013;3:e003650.

32 Liem TBY, Slob EMA, Termote JUM, et al. Comparison of antibiotic dosing recommendations for neonatal sepsis from established reference sources. Int J Clin Pharm 2018;40:436-43.

33 Bolisetty S. Australasian neonatal medicines formulary (ANMF), 2019. Available: https://www.seslhd.health.nsw.gov.au/royalhospital-for-women/australasian-neonatal-medicines-formularyanmf [Accessed $10 \mathrm{Jul}$ 2019].

34 Klingenberg C, Kornelisse RF, Buonocore G, et al. CultureNegative Early-Onset Neonatal Sepsis - At the Crossroad Between Efficient Sepsis Care and Antimicrobial Stewardship. Front Pediatr 2018:6:285

35 Folgori L, Ellis SJ, Bielicki JA, et al. Tackling antimicrobial resistance in neonatal sepsis. Lancet Glob Health 2017;5:e1066-8.

36 ACSQHC. Aura 2017: second Australian report on antimicrobial use and resistance in human health. Sydney: Australian Commission on Safety and Quality in Health Care, 2017. 